Borneo Journal of Sciences \& Technology, 3(2): 01-04

DOI: http://doi.org/10.3570/bjost.2021.3.2-01

e-ISSN: 2672-7439

(C) 2018, UCTS Publisher.

Submitted: $20^{\text {th }}$ December 2020

Accepted: $25^{\text {th }}$ March 2021

Published: $31^{\text {st }}$ July 2021

\title{
Dispersal Potential Index (DPi) As Alternative Indicator for Coral Larvae Dispersal Potential
}

${ }^{1,2 *}$ Muhammad Faiz Mohd Hanapiah, ${ }^{1}$ Shahbudin Saad, ${ }^{2}$ Zuhairi Ahmad and ${ }^{1,2}$ Mohd Zaini Mustapa

${ }^{1}$ Department of Marine Science, Kulliyyah of Science, International Islamic University Malaysia, Jalan Sultan Ahmad Shah, Bandar Indera Mahkota, 25200 Kuantan Pahang

${ }^{2}$ Remote Sensing, GIS and Physical Oceanography Modelling Laboratory, Department of Marine Science, Kulliyyah of Science, International Islamic University Malaysia, Jalan Sultan Ahmad Shah, Bandar Indera Mahkota, 25200 Kuantan Pahang

\begin{abstract}
Dispersal of coral larvae is influence by combination of multiple factors, yet comparisons are commonly displayed on two- or three-dimensional charts (i.e.: pelagic larvae duration vs. distance). Therefore, the present study implies the application of Dispersal Potential Index (DPi) based on the factors which influence the dispersal range and potential such as pelagic larvae duration (PLD), adult coral cover, current speed and depth variations. Each factor was given score from 1 to 10 based on their influence towards dispersal potential. The DPi was able to describe dispersal potential of Acropora larvae from two separated reef sites (Bidong Island and Kuantan Coastal Waters) which share common hydrodynamic pattern. It is suggested that Acroporid larvae in Kuantan coastal waters has greater dispersal potential than Bidong Island. DPi for Kuantan coastal waters was classified as intermediate dispersal range while DPi and Bidong Island was categorized as short dispersal range. This approach is arguably the first of its kind in describing the multiple factors for dispersal of coral larvae. The application of DPi is important especially for reef managers to estimate dispersal range of coral for a better marine ecosystem management.
\end{abstract}

Keywords: Dispersal potential index, Coral larvae dispersal, Coral reef, Ecosystem management

\section{INTRODUCTION}

Connectivity plays a vital role in sessile marine invertebrate ecology. For non-migratory organisms such as coral reef which physically attached to the substrate, connectivity relies heavily on dispersal of coral larvae. Coral life cycle involves benthic polyp phase and planula larval phase. Broadcasting coral such as Acropora, which encompasses most coral species release larvae into the water column during mass spawning season. During this early life stage, most of the coral larvae are unable to swim horizontally to reach settlement sites and thus depend on the prevailing current as main dispersal transport. These larvae may dispersed in an extensive range of distance from a few meters to hundreds of kilometers before successful settlement depending on the current pattern during planktonic stage [1].

Simulating dispersal pattern for coral larvae requires an advanced biophysical modelling approaches such as those reported in Kuantan coastal region [2] and southern part of Singapore [3]. Such modelling approaches require high level of hydrodynamic modelling knowledge with advanced simulation software and tools. Therefore, a much simpler larvae dispersal estimation by using radar chart to describe coral larvae dispersal potential without having to undergone series of process to establish a larvae dispersal model is needed. This would give advantages to reef managers to plan for future ecosystem management based on the data available during their coral reef monitoring framework (coral distribution and depth estimation).

\section{MATERIALS AND METHODS}

\section{Factors influencing dispersal potential}

The distribution pattern of adult coral cover (\%) is considered as one of important factors in influencing dispersal of coral larvae. The number of existing adult coral may reflect coral fecundity (the ability to produce an abundance of offspring) [4]. Therefore, ecological modelling suggested the abundance of adult coral (adult

Corresponding Author: Muhammad Faiz Mohd Hanapiah. International Islamic University Malaysia (IIUM)

Email: faizhanapiah@iium.edu.my 


\section{Dispersal Potential Index (DPi) As Alternative Indicator for Coral Larvae Dispersal Potential}

coral cover) shall be proportionate with the number of larvae release [3]. It is postulated that a higher coral cover might increase dispersal potential since more larvae would survive during larval transport.

The length of pelagic larvae duration (PLD) is thought to influence dispersal in which longer PLD may have greater dispersal distance. This has been initial assumption from the ecologist who conducted numerous experiments on pelagic larvae duration for estimating coral larvae dispersal potential [5,6]. For instance, it is suggested that Acropora could travel up to hundreds of kilometers from source reef due to its extensive dispersal potential [6]. Previous works on larval competency indicated that optimal PLD for broadcast spawning coral ranged between $2-20$ days after spawning (DAS) [7].

Broadcasting coral such as Acropora, which encompasses most coral species release larvae into the water column during mass spawning season. During this early life stage, most of the coral larvae are unable to swim horizontally to reach settlement sites and thus depend on the prevailing current as main dispersal transport. These larvae may disperse in an extensive range of distance from a few meters to hundreds of kilometers before successful settlement depending on the current pattern during planktonic stage [1]. Higher current speed might result in greater dispersal distance. In this case, current speed was scored between $0.1 \mathrm{~m} / \mathrm{s}$ until $0.5 \mathrm{~m} / \mathrm{s}$ based on the current speed range from hydrodynamic model for Kuantan coastal waters [8]. This current speed range is comparable with current speed range model in the east coast Peninsular Malaysia [9];[10].

Lastly, depth variation also is being considered as factors since shallower reef area often have slower current speed due to higher bed-resistance and often subjected with higher local retention compared to deeper area. The influence of bathymetry on ocean circulation has been demonstrated by in tidally forced atoll in Australia [11]. In this case, the depth range considered was set between 2 to $20 \mathrm{~m}$ since this range is ideal for coral reef monitoring survey and recreational scuba diving.

\section{DPi score chart}

The summary of score for each factor is tabulated in Table 1. Based on the score given, three types of combination were suggested as the benchmark categories for dispersal potential (short, intermediate or long dispersal distance). The proposed score values and resulting dispersal potential index (DPi) are demonstrated in Table 2 and Figure 1 respectively.

\section{RESULTS AND DISCUSSION}

The proposed Dpi can be used by reef managers to assess dispersal potential capacity different targeted species or genus based on the criteria suggested. This index also can assess Dpi capacity for the same coral species but with different dispersal factors score. DPi for similar genus from different spatial setting and abundance would varies since adult percentage cover, current speed and depth might varies spatially. For comparison, DPi for Acropora from Kuantan coastal waters [2] were compared with Bidong Island [12] based on dispersal factors score (adult cover, current speed and depth) and demonstrated in Table 3.

Based on the present $\mathrm{DPi}$, it is suggested that Acroporid larvae in Kuantan coastal waters has greater dispersal potential than Bidong Island. DPi for Kuantan coastal waters was classified as intermediate dispersal range category as shown in Figure 2a. It can be postulated that most of the larvae will be dispersed far from natal reef. On the contrary, Dpi for Acroporid in Bidong Island was classified as short dispersal range in Figure $2 \mathrm{~b}$. Therefore, it can be generally assumed that larvae from this location could have shorter dispersal range and some of them might recruits near natal reef although without applying dispersal model. While estimation of dispersal potential based on the proposed DPi may have its own limitations, this approach still able to produce general idea on the dispersal capacity of coral larvae especially along the coastal area in the east coast of Peninsular Malaysia which share similar hydrodynamic regime. The influence of dispersal factors (adult abundance, PLD, current speed and depth variation) towards dispersal capacity is well described throughout dispersal of coral larvae study in Kuantan coastal waters [2]. 
Dispersal Potential Index (DPi) As Alternative Indicator for Coral Larvae Dispersal Potential

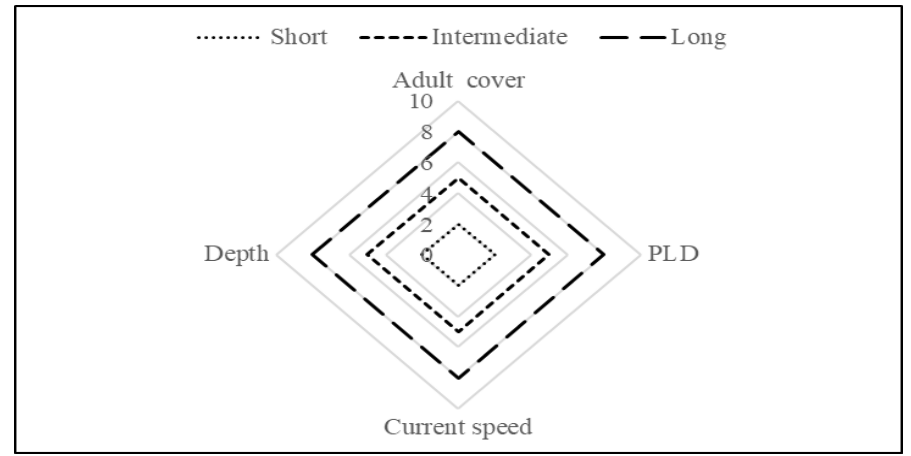

Figure 1: Dpi range proposed in this study

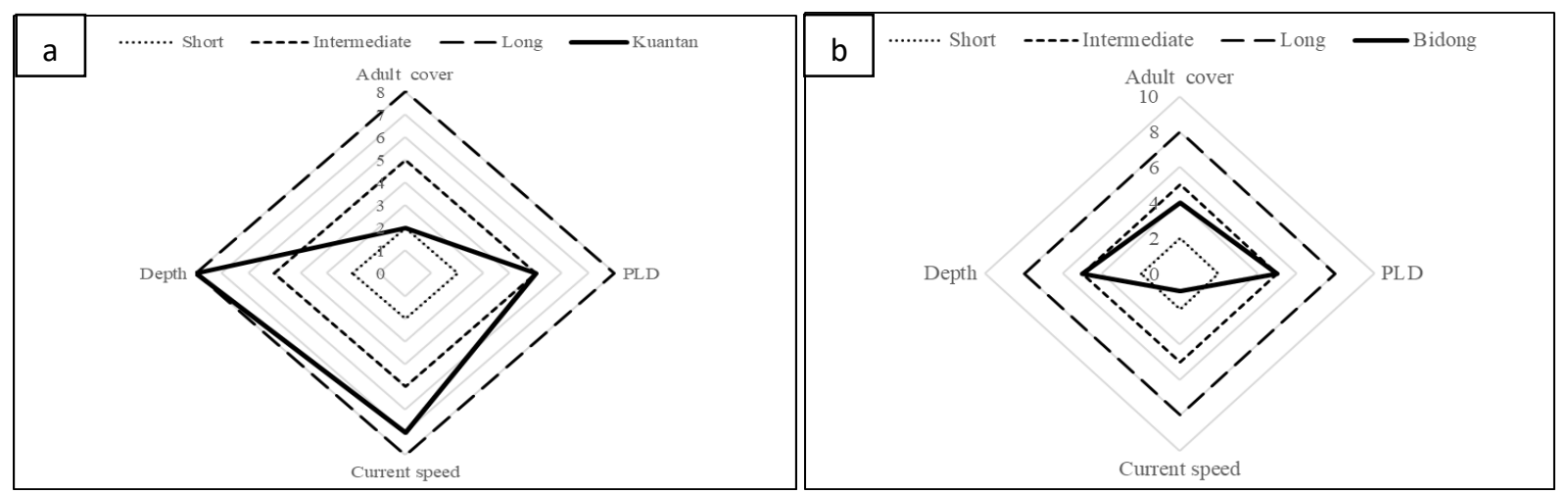

Figure 2: DPi score of Acropora in a) Kuantan coastal waters and b) Bidong Island

Table 1: Summary of score for factors considered in DPi

\begin{tabular}{|r|c|c|c|c|}
\hline Scale & Adult cover (\%) & PLD (Day) & Current speed (m/s) & Depth (m) \\
\hline 1 & $0-10$ & $<2$ & $<1$ & 2 \\
\hline 2 & $11-20$ & 2 & 0.1 & 4 \\
\hline 3 & $21-30$ & 4 & 0.15 & 8 \\
\hline 4 & $31-40$ & 6 & 0.2 & 10 \\
\hline 5 & $41-50$ & 8 & 0.25 & 12 \\
\hline 6 & $51-60$ & 10 & 0.3 & 14 \\
\hline 7 & $61-70$ & 12 & 0.35 & 16 \\
\hline 8 & $71-80$ & 14 & 0.4 & 18 \\
\hline 9 & $80-90$ & 16 & 0.45 & 20 \\
\hline 10 & $90-100$ & 18 & 0.5 & \\
\hline
\end{tabular}

Table 2: Proposed score value for DPi range

\begin{tabular}{|l|c|c|c|}
\hline Factors & Short & Intermediate & Long \\
\hline Adult cover & 2 & 5 & 8 \\
\hline PLD & 2 & 5 & 8 \\
\hline Current speed & 2 & 5 & 8 \\
\hline Depth & 2 & 5 & 8 \\
\hline
\end{tabular}


Dispersal Potential Index (DPi) As Alternative Indicator for Coral Larvae Dispersal Potential

Table 3: DPi factor score comparison between Kuantan coastal waters and Bidong Island

\begin{tabular}{|l|c|c|c|c|}
\hline Reef Location & \multicolumn{2}{|c|}{ Kuantan coastal water } & \multicolumn{2}{c|}{ Bidong Island } \\
\hline Factors & Acropora & Score & Acropora & Score \\
\hline Adult cover & 16.6 & 2 & 32.9 & 4 \\
\hline PLD & 8 & 5 & 8 & 5 \\
\hline Current speed & 0.35 & 7 & 0.06 & 1 \\
\hline Depth & 16 & 8 & 10 & 5 \\
\hline
\end{tabular}

\section{CONCLUSION}

The DPi introduced in this study can emerge as reliable guideline in estimating dispersal pattern along the coastal region. This approach is arguably the first of its kind in describing the multiple factors for dispersal of coral larvae. The application of DPi is important especially for reef managers to estimate dispersal range of coral for a better marine ecosystem management. Nevertheless, further validation of the DPi estimation using actual larvae dispersal modelling is needed especially in other reef locations.

\section{ACKNOWLEDGMENT}

We would like to thank the Department of Marine Science, Kulliyyah of Science, International Islamic University Malaysia. This project was funded by EScience Grant (SF16-002-0071) under Ministry of Science, Technology and Innovation, Malaysia.

\section{REFERENCES}

[1] Cowen, R. K., Paris, C. B. and Srinivasan, M. 2006. Scaling of connectivity in marine populations. Science, 311(5760): 522-527.

[2] Hanapiah M. F. M., Saad, S., and Ahmad, Z. 2020. Dispersal pattern of coral larvae in Kuantan coastal waters, Malaysia. Science Heritage Journal, 4(1): 13-18.

[3] Tay, Y., Todd, P., Rosshaug, P., Chou, L. 2012. Simulating the transport of broadcast coral larvae among the Southern Islands of Singapore. Aquatic Biology, 15(3): 283-297.

[4] Hughes, T. P., Baird, A. H., Dinsdale, E. A., Moltschaniwskyj, N. A., Pratchett, M. S., Tanner, J. E., Willis, BL. 2000. Supply-side ecology works both ways: The link between benthic adults, fecundity, and larval recruits. Ecology, 81(8):2241-2249.

[5] Nozawa, Y., Harrison, P. L. 2002. Larval settlement patterns, dispersal potential, and the effect of temperature on settlement of larvae of the reef coral, Platygyra daedalea, from the Great Barrier Reef. Proceedings 9th International Coral Reef Symposium, Bali:409-415.

[6] Graham, E. .M, Baird, A. H., Willis, B.L., and Connolly, S. R. 2013. Effects of delayed settlement on post-settlement growth and survival of scleractinian coral larvae. Oecologia, 173(2):431438.

[7] Nozawa, Y., Okubo, N. 2011. Survival Dynamics of Reef Coral Larvae with Special Consideration of Larval Size and the Genus Acropora. Biological Bulletin, 220(1):15-22.

[8] Hanapiah M. F. M., Saad, S, Ahmad, Z. 2020. Hydrodynamic Modelling in Inshore Reef Area within Kuantan Coastal Region. Journal CleanWAS, 4(1):1-7.

[9] Daud, N.,R., Akhir, M. F., Husain, M. L. 2016. Water circulation in the shallow shelf areas off the Terengganu coast affected by wind stress force using a hydrodynamic model, Journal of Sustainable Science Management, 1:81-92.

[10] Akhir, M. F. M., Zakaria, N. Z. and Tangang F. 2014. Intermonsoon Variation of Physical Characteristics and Current Circulation along the East Coast of Peninsular Malaysia. International Journal of Oceanography, 2014:1-9.

[11] Green, R. H., Lowe, R. J., Buckley, M. L. 2018. Hydrodynamics of a Tidally Forced Coral Reef Atoll. Journal of Geophysical Research: Oceans, 123(10):7084-7101.

[12] Husaini MR., 2016. Spatio-temporal variation of scleractinian coral recruitment in Balok coastal waters and Bidong Island, Malaysia. M.S. Thesis, International Islamic University Malaysia, Kuantan, Pahang. 